\title{
IMPLEMENTASI PROGRAM KAMPUNG IKLIM: URBAN FARMING MELALUI HIDROPONIK DAN BUDIKDAMBER DI KELURAHAN SIALANG PALEMBANG
}

\author{
Trecy Austin ${ }^{*}$ \\ Marleni $^{2}$ \\ 1 Ilmu Administrasi Negara, STISIPOL Candradimuka, Palembang, Indonesia \\ 2IImu Komunikasi, STISIPOL Candradimuka, Palembang, Indonesia \\ trecy.austin@gmail.com $^{1 *}$ ) \\ $\left.\underline{\text { marleni.oke@gmail.com }}^{2}\right)$
}

Kata Kunci: [Proklim, Urban Farming, Hidroponik dan BUDIKDAMBER]
Abstrak: Pandemi Covid 19 membuat Masyarakat lebih disibukkan di rumah dibanding di luar rumah. Salah satu komponen peningkatan Ketahanan Pangan dalam Adaptasi Perubahan Iklim mendukung Program Kampung Iklim yaitu dengan penerapan Urban Farming. suatu konsep pertanian atau perkebunan yang dilakukan dengan memanfaatkan lahan yang terbatas. Urban farming disebut juga pertanian kota, menurut para ahli pengertian urban farming atau urban agriculture sebagai kegiatan membudidayakan tanaman atau memelihara hewan ternak didalam dandisekitar wilayah kota besar (metropolitan). Metode pelaksanaan, Kegiatan Pemberdayaan Masyarakat dilaksanakan dengan melakukan kegiatan pelatihan, dan pendampingan praktek langsung. Masyarakat memahami perihal Urban Farming yang meliputi cara penerapan khususnya mengenai Hidroponik dan BUDIKDAMBER, serta manfaatnya bagi kesehatan dan ekonomi tingkat rumah tangga. Masyarakat RT 19 dan RT 65 RW 13 Kelurahan Sialang Kecamatan Sako Kota Palembang berorientasi untuk maju dalam memulai dan menerapkan Hidroponik dan BUDIKDAMBER di rumah tangga masing-masing.

Published by:

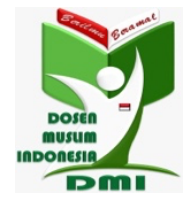

Copyright (c) 2021 The Author(s)

This article is licensed under CC BY 4.0 License

\section{(cc) $\mathrm{EY}$}

https://dmi-journals.org/jai/ 


\section{Pendahuluan}

Urban Farming (Pertanian Perkotaan) merupakan kegiatan pertumbuhan, pengeloaan dan distribusi pangan melalui budidaya tanaman dan peternakan yang intensif di perkotaan. Peningkatan Pengetahuan dan keterampilan Masyarakat menjadi penting, guna meningkatkan kompetensi di Masa Covid 19. Paradigma bahwa petani sangat lekat dengan lumpur, tidak memiliki masa depan dan erat dengan kemiskinan dan tidak mampu mensejahterakan menghambat generasi muda ikut serta dalam Program Kampung Iklim. Tantangan saat ini adalah bagaimana kaum muda mau mengambil peran dalam kegiatan Program Kampung Iklim. Pertambahan jumlah penduduk yang bergerak sangat cepat mengakibatkan kebutuhan akan pemukiman dan lapangan pekerjaan yang dibutuhkan sangat tinggi, ditambah dengan kondisi pandemi Covid 19 banyak Masyarakat kena PHK, dan menurunnya pemasukkan keuangan bagi para Pengusaha atau UMKM.

Berbagai usaha telah dilakukan Pemerintah dalam menangani keterbatasan di perkotaan Palembang, sebagai pusat administrasi daerah di Provinsi Sumatera Selatan. Adapun data lahan di Kota Palembang Tahun 2016-2019 dapat dilihat dalam Tabel 1.

Tabel 1. Data Lahan Pertanian Kota Palembang Tahun 2016-2019

\begin{tabular}{lrrrrr}
\hline No & Tahun & $\begin{array}{c}\text { Tegal/Kebun } \\
(\text { Ha) }\end{array}$ & $\begin{array}{r}\text { Ladang/Huma } \\
(\mathrm{Ha})\end{array}$ & $\begin{array}{c}\text { Sementara Tidak } \\
\text { Digunakan (Ha) }\end{array}$ & Jumlah (Ha) \\
\hline 1 & 2016 & 1.652 & 566 & 2.380 & 4.598 \\
2 & 2018 & 863 & 1136 & 952 & 2.951 \\
3 & 2019 & 1.085 & 655 & 669 & 2.409 \\
\hline
\end{tabular}

Sumber: Badan Pusat Statistik Provinsi Sumatera Selatan, 2020

Salah satu komponen peningkatan Ketahanan pangan dalam Adaptasi Perubahan Iklim mendukung Program Kampung Iklim yaitu dengan penerapan Urban Farming. Urban Farming merupakan suatu konsep pertanian atau perkebunan yang dilakukan dengan memanfaatkan lahan yang terbatas. Urban Farming disebut dengan pertanian Kota. Kegiatan membudiyakan tanaman ini guna memperoleh bahan pangan atau kebutuhan lain termasuk tambahan finansial. Berdasarkan hasil koordinasi dan survei lokasi di RT 19 dan RT 65 Kelurahan Sialang Kecamatan Sako Kota Palembang. Pemberdayaan masyarakat ini memberikan edukasi Urban Farming dengan penerapan hidroponik dan BUDIKDAMBER.

Kegiatan Urban Farming dapat menjadi salah satu solusi mengatasi perekonomian Masyarakat yang menurun selama Pandemi Covid 19. Namun, perlu dilakukan pelatihan untuk meningkatkan pengetahuan generasi muda dalam hal ini Mahasiswa bersama Masyarakat untuk pelaksanaan Urban Farming. Konsep Urban Farming ini telah lama diterapkan di dunia pertanian. Tujuan dari penerapan kegiatan Urban Farming ini, yaitu:

1. Melakukan Program Kampung Iklim melalui Pengembangan Hidroponik dan BUDIKDAMBER di RT 19 dan 65 RW 3 Kelurahan Sialang. 
2. Memberikan edukasi langsung tentang penerapan Urban Farming pada Masyarakat khususnya teknis pelaksanaan Pengembangan Hidroponik dan BUDIKDAMBER.

3. Menambah kontribusi ketahan pangan rumah tangga,

4. menambah penghasilan Masyarakat sekitar apabila membuat inovasi tambahan jangka panjang.

Manfaat Pengabdian Masyarakat ini agar Masyarakat memanfaatkan lahan di depan rumah sebaik mungkin dengan pemanfaatan barang bekas dirumah. Konsep Urban Farming yang kita ketahui bahwa melakukan kegiatan budidaya dengan memanfaatkan lahan yang terbatas agar berdaya guna dan memiliki nilai tambah. Bentuk kegiatan beranekaragam, seperti, Hidroponik (budidaya pertanian berbasis air), aeroponik (budidaya pertanian berbasis udara), vertikultur (budi daya pertanian yang dilakukan dengan menyusun tanaman secara bertingkat dari bawah ke atas). Pemanfaatan lahan terbatas dapat dilakukan melalui pemanfaatan bagian atap rumah dan pagar sebagai lahan budidaya, pemanfaatan dinding sebagai lahan pertanian. Pemanfaatan sampah sebagai alat dan sarana juga dilakukan, karena pada kegiatan ini menggunakan stereofoam bekas, botol plastik bekas, gabus (pengemasan buah), kaleng bekas dan juga pralon untuk menjadi wadah budidaya pertanian.

\section{Metode Pelaksanaan}

\section{Tempat dan Waktu}

Lokasi yang menjadi tempat pengabdian masyarakat di RT 19 dan RT 65 Kelurahan Sialang Kecamatan Sako. Wilayah kelurahan sialang Palembang tidak jauh dari Kantor Kecamatan Sako dengan luas wilayah 291 Ha. Adapun Peta lokasi dan Gambar Situasi Kantor Kelurahan dapat dilihat pada Gambar 1.

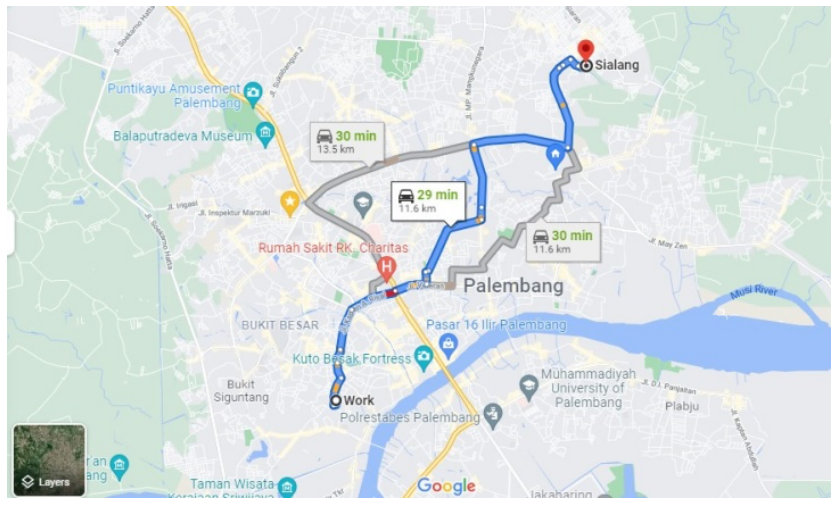

Gambar 1. Peta Lokasi Kelurahan Sialang

\section{Khalayak Sasaran}

Kegiatan ini mengikutsertakan Bapak, Ibu dan anak muda yang berdampak Covid 19 sebagai perwakilan dari RT 19 dan RT 65 RW 13 Kelurahan Sialang Kecamatan Sako Palembang. Adapun data dari Masyarakat berdasarkan Usia dapat dilihat di Tabel 2.

Tabel 2. Data Masyarakat Berdasarkan Usia

\begin{tabular}{cccc}
\hline No & Usia & Jumlah & Persentase (\%) \\
\hline 1 & $20-30$ & 5 & 21,7 \\
\hline
\end{tabular}




\begin{tabular}{cccc}
\hline No & Usia & Jumlah & Persentase (\%) \\
\hline 2 & $31-40$ & 8 & 34,7 \\
3 & $40>$ & 10 & 43,4 \\
& Total & 23 & 100 \\
\hline
\end{tabular}

Sumber: Diolah Penulis Tahun 2021

Waktu Pelaksanaan kegiatan Pemberdayaan Masyarakat dilakukan selama 30 hari pada bulan September 2021 yang mana disusun berdasarkan kondisi terkini di lapangan dengan rincian dapat dilihat pada Tabel 3.

Tabel 3. Waktu Kegiatan

\begin{tabular}{l}
\multicolumn{1}{c}{ Jenis Kegiatan } \\
\cline { 2 - 3 } \\
\cline { 2 - 3 }
\end{tabular}

Sumber: Diolah Penulis Tahun 2021

\section{Metode Pengabdian}

Kegiatan Pemberdayaan Masyarakat dilaksanakan dengan melakukan kegiatan pelatihan, pendampingan serta penyuluhan dalam membuang sampah pada tempatnya. Kegiatan yang dilaksanakan meliputi, Pemberdayaan masyarakat untuk peningkatan perubahan pola pikir masyarakat agar berkembang dan bertahan di masa pandemi covid 19, dan Pelestarian lingkungan dengan memakai sampah atau sisa kain bekas yang ada dirumah. Secara rinci metode pelaksanaan kegiatan diantaranya yaitu: 
a. Kajian Literatur dilakukan untuk mengetahui beberapa hal mengenai Program Kampung Iklim seperti: Adaptasi, dan Mitigasi.

b. Survei Lokasi menjadi langkah awal supaya kegiatan dapat berjalan lancar.

c. Sosialisasi di awal kegiatan kepada Ketua RT 19 dan RT 65, terkait tujuan kegiatan, tahapan kegiatan dan jadwal kegiatan.

d. Edukasi secara tatap muka terhadap Masyarakat yang berjumlah 23 orang, dalam kegiatan dibagi menjadi beberapa kelompok kecil.

e. Membangun kembali karakter bangsa indonesia dari Pancasila yaitu Gotongroyong. Bersama-sama warga dan Mahasiswa membangun lingkungan yang bersihd an hijau. Saling menjaga kelestarian lingkungan rumah untuk membuang sampah pada tempatnya dan menjadikan barang plastik bekas menjadi barang yang bermanfaat.

\section{f. Pendampingan dan Prakter Langsung}

Penyelesaian masalah ini tidak semata-mata dilakukan hanya untuk kebutuhan penulisan, namun dilaksanakan secara langsung dengan pendampingan anak pertanian dan praktek langsung dilakukan selama kurang lebih 30 Hari.

\section{Indikator Keberhasilan}

Indikator keberhasilan produk kegiatan Pemberdayaan Masyarakat ini, yaitu:

a. Terlaksananya kegiatan edukasi Hidroponik dan BUDIKDAMBER, wujud pelaksanaan Urban Farming di RT 19 dan RT 65 RW 13 Kelurahan Sialang Kecamatan Sako sebagai media edukasi dan wisata.

b. Meningkatnya produksi tanaman hortikultura dan perikanan skala rumah tangga di wilayah Kelurahan Sialang Kecamatan Sako Kota palembang.

c. Meningkatkan pengetahuan dan motivasi serta minat masyarakat tetang Urban Farming (Hidroponik dan BUDIKDAMBER).

d. Meningkatkan kesadaran masyarakat dalam menjaga dan melestarikan lingkungan melalui pemanfaatan barang-barang bekas.

e. Meningkatkan tingkat konsumsi tanaman hortikultura dan mengurangi resiko anak stanting di tingkat rumah tangga.

f. Dihasilkan video dokumentasi tentang penerapan Urban Farming melalui pengembangan Hidroponik dan BUDIKDAMBER.

\section{Hasil dan Pembahasan}

Segala Kegiatan Pengembangan Hidroponik dan BUDIKDAMBER dilakukan dengan bantuan Mahasiswa/i Kelompok 11 Kampus STISIPOL Candradimuka Palembang. Dibawah arahan dan konsultasi dengan narasumber yaitu pelaku usaha hidroponik Adriansyah Maulana, SP. Sasaran dalam kegiatan penerapan Urban Farming Pengembangan Hidroponik dan BUDIKDAMBER dengan barang-barang bekas di RT 19 dan RT 65 RW 13 Kelurahan Sialang Kecamatan Sako Kota Palembang adalah seluruh masyarakat di wilayah RT 19 dan RT 65 RW 13 Kelurahan Sialang Kecamatan Sako Kota Palembang dan sekitarnya.

Hasil Kegiatan diawali dengan survei lokasi dan koordinasi dengan pemilik wilayah setempat yaitu RT dan RW serta tokoh masyarakat yang ada, kemudian dilanjutkan dengan sosialisasi tentang program kerja yang akan dilakukan dan 
kemudian dilakukan persiapan perlengkapan dan pembuatan Hidroponik serta BUDIKDAMBER. Dalam kegiatan Hidroponik kami melakukan pertanaman tanaman hortikultura diantaranya tanaman bayam dan kangkung. Kemudian dilanjutkan dengan pelaksanaan kegiatan BUDIKDAMBER, dalam hal ini budidaya yang dilakukan adalah budidaya ikan lele. Persiapan dan pelaksanaan dilakukan secara gotong royong oleh peserta KKN dan dibantu oleh masyarakat sekitar RT 19 dan RT 65 RW 13 Kelurahan Sialang. Selanjutnya dilakukan juga kegiatan Senam Bersama dan Gotong Royong pembersihan wilayah sekitar, diharapkan dengan kegiatan ini para peserta KKN dapat bersosialisasi lebih dekat dengan masyarakat dan dapat memberikan contoh untuk menjaga kesehatan dan kebersihan lingkungan. Sebagai identitas lokasi maka dibuatkan pula palang nama untuk kegiatan yang dilakukan, dan di akhir kegiatan kami melakukan pendataan kepada masyarakat perihal kondisi administratif dan ekonomi masyarakat sekitar, khususnya yang mengalami dampak dari Covid-19.

Hasil dari kegiatan ini ialah menghasilkan produk tanaman hotikultura dan perikanan air tawar dan menyerahkan sepenuhnya hasil tersebut kepada Ketua RT setempat agar dapat dipergunakan dan dikembangkan oleh masyarakat sekitar, serta pengambilan gambar beserta video hasil pelaksanaan Pengabdian Masyarakat, diharapkan kedepannya Masyarakat tetap dapat menjalin hubungan yang baik dengan kampus STISIPOL Candradimuka Palembang. Adapun kegiatan tersebut telah dirangkum pada Gambar dibawah ini.

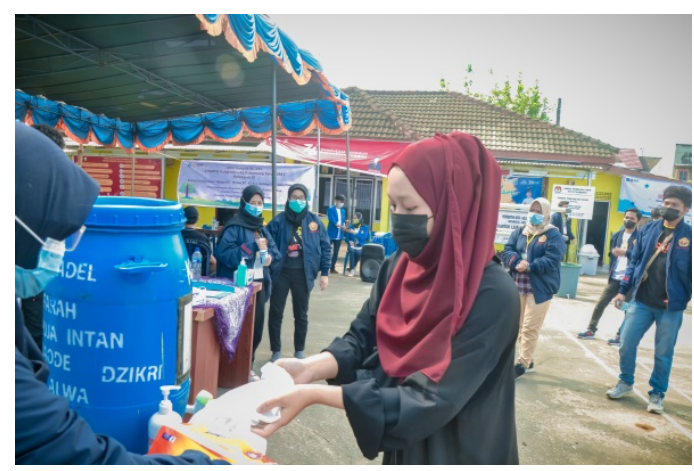

Gambar 2. Keadaan Depan Kantor Kelurahan Sialang

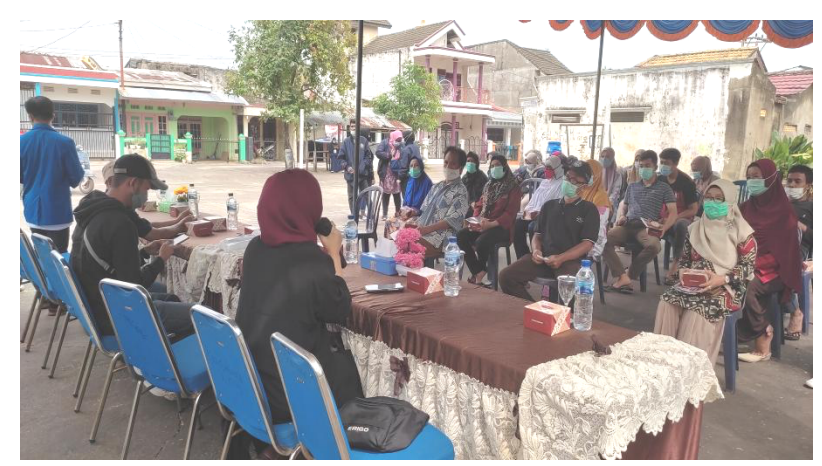

Gambar 3. Pengenalan Awal di depan Kantor Kelurahan Sialang 


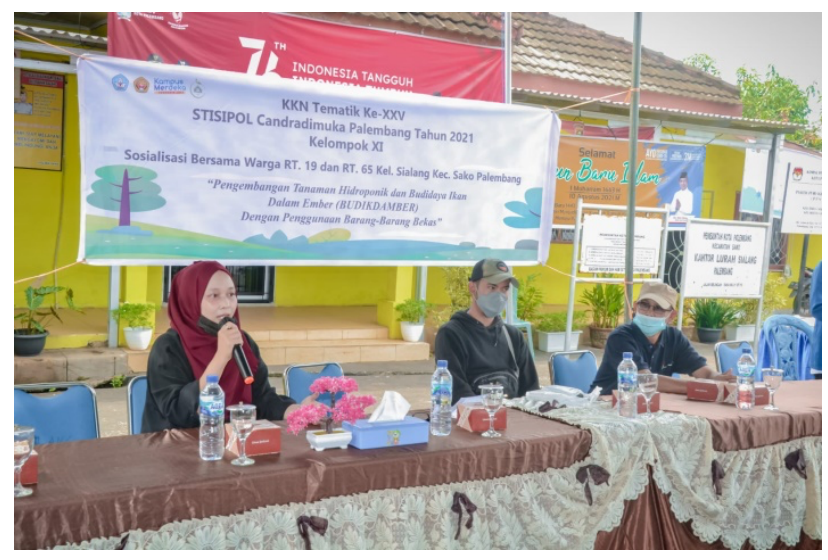

Gambar 4. Edukasi secara tatap muka

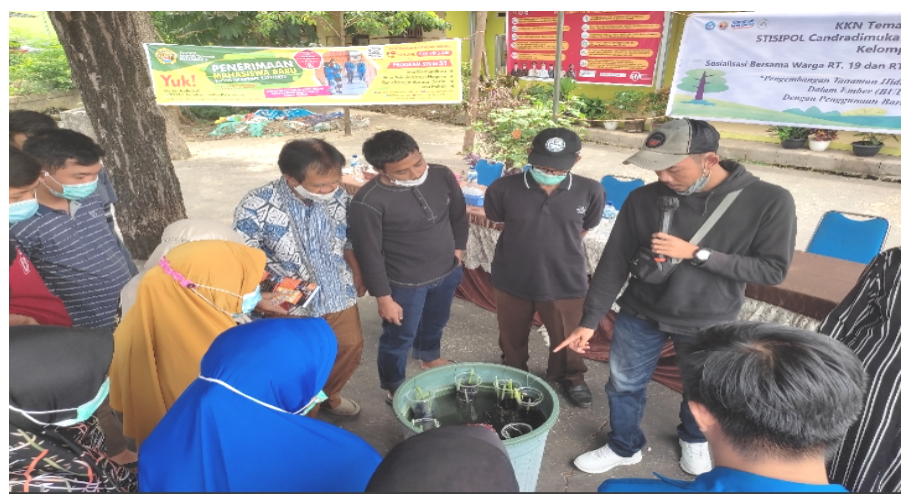

Gambar 5. Pendampingan dan Praktek Langsung
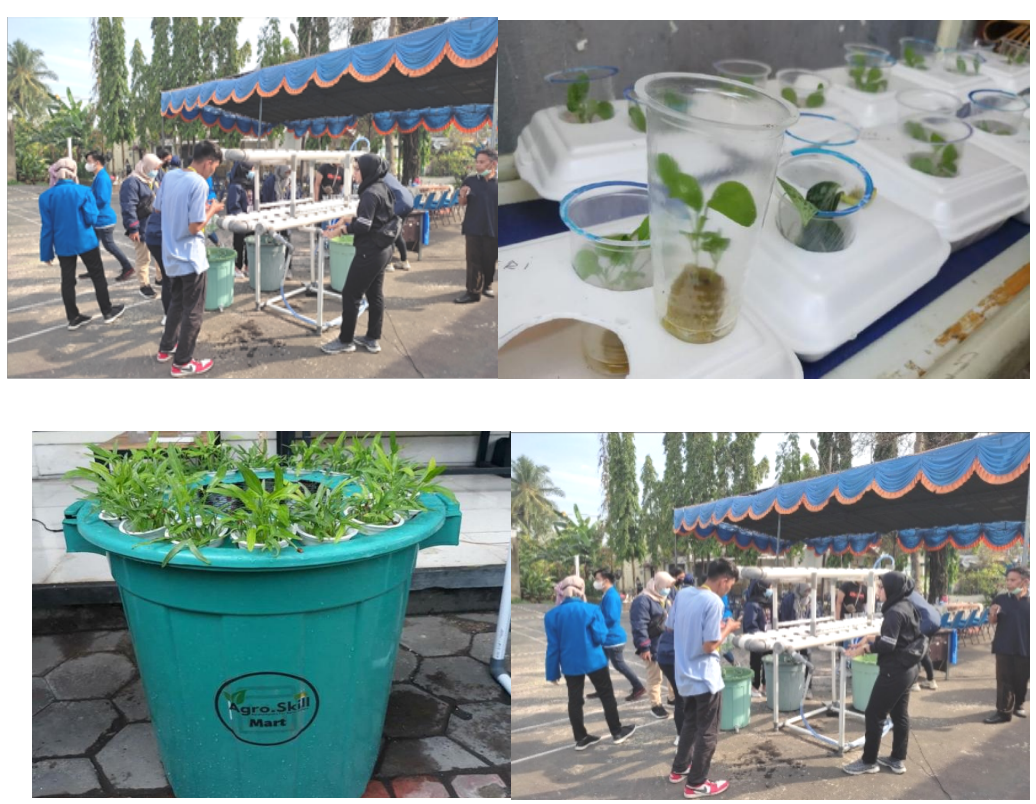

Gambar 6. Hasil Kegiatan Pemberdayaan Masyarakat 


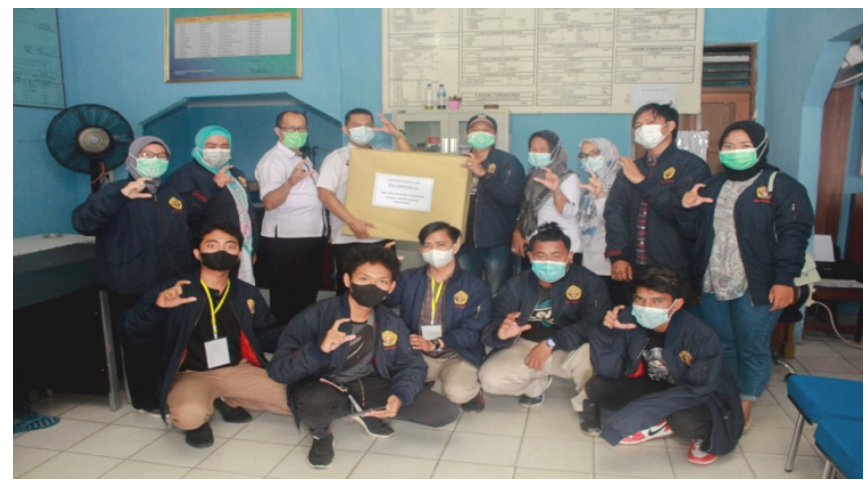

Gambar 5. Foto bersama Bapak Lurah

\section{Kesimpulan}

Kelurahan Sialang Kecamatan Sako Kota palembang, terkhususnya di wilayah RT 19 dan RT 65 RW 13 secara umum memiliki potensi yang besar dalam menerapkan Urban Farming melalui pengembangan hidroponik dan BUDIKDAMBER, hanya saja masih belum cukup edukasi dan motivasi sehingga masyarakat tidak mengetahui teknis dan manfaat dari Hidroponik dan Budikdaper. Melalui kehadiran mahasiswa KKN Tematik STISIPOL Candradimuka Palembang Tahun 2021 memberikan pembekalan ilmu tentang cara penerapan Urban Farming melalui pengembangan Hidroponik dan BUDIKDAMBER di RW 19 dan RT 65 RW 13 Kelurahan Sialang Kecamatan Sako Kota Palembang ini, mulai dari pengertian, manfaat, teknis pelaksanaan, jenis tanaman yang sesuai, jenis ikan yang sesuai dan perawatan yang baik. Sehubungan dengan hal tersebut maka kegiatan KKN Tematik ini terlah berhasil dilaksanakan dengan baik dalam membantu pengembangan Hidroponik dan BUDIKDAMBER dengan memanfaatkan barang-barang bekas di RT 19 dan RT 65 RW 13 Kelurahan Sialang Kecamatan Sako Kota Palembang.

Adapun saran-saran dari kegiatan yang dilakukan adalah sebagai berikut:

1. Masyarakat RT 19 dan RT 65 RW 13 Kelurahan Sialang Kecamatan Sako Kota Palembang harus berorientasi untuk maju dalam memulai dan menerapkan Hidroponik dan BUDIKDAMBER di rumah tangga masing-masing.

2. Pemerintah kelurahan diharapkan agar dapat memfasilitasi masyarakat untuk mendapatkan pelatihan-pelatihan agar masyarakat dapat berkembang dalam pengembangan Hidroponik dan BUDIKDAMBER dari barang-barang bekas.

3. Pemerintah kelurahan bersama Ketua RT dan masyarakat agar mempertahankan dan mengembangkan Hidroponik dan BUDIKDAMBER dari barang-barang bekas yang sudah terbangun agar berkelanjutan.

\section{Ucapan Terimakasih}

Kami mengucapkan terimakasih kepada semua pihak yang terkait, kepada:

1. Bapak Dr. Amiruddin Sandy, M.Si., selaku Camat Sako Kota Palembang yang memberikan ruang kepada Dosen dan Mahasiswa/I untuk ikut serta Pengabdian Masyarakat. 
2. Bapak Very Suparja, S.E., selaku Lurah Sialang, Kecamatan Sako Kota Palembang yang menyempatkan ikut serta hadir selama kegiatan berlangsung.

3. Ketua RT 19, dan Ketua RT 65, ikut menyemarakkan kegiatan Pengabdian Masyarakat dan memberikan ruang untuk kelancaran selama kegiatan.

4. Seluruh Masyarakat yang telah hadir dan berpartisipasi selama kegiatan berlangsung.

5. Tidak lupa, Seluruh Mahasiswa kelompok 11, yang tidak bisa disebutkan satu persatu.

\section{Referensi}

Audit Yulardi, Andar Bagus, dan Dwinita Larasati. 2017. Pengaruh Efisiensi Waktu Pada Sistem Pengairan Satu Titik Sarana Tanam Vertikal Terhadap Perubahan Aktivitas Menyiram Tanaman Oleh Masyarakat Kampung Kota. Diakses pada tanggal 2 November 2021.

Badan Pusat Statistik (BPS). 2005. Data Penyusutan Lahan Sawah di Pulau Jawa yang terkonversi Tahun 1979-2004. Publikasi BPS diakses dari http://www.bps.go.id/. Diakses pada tanggal 26 September 2021.

Badan Pusat Statistik (BPS) Provinsi Sumatera Selatan. 2020. Data Luas Lahan Pertanian di Provinsi Sumatera Selatan. Subject 53 BPS diakses dari http://www.sumsel.bps.go.id/ , diakses pada tanggal 26 September 2021 pada jam 13.00 WIB.

Bareja, Ben G. 2010. Intensify Urban Farming, Grow Crops in The City. Tersedia dalam http://www.cropsreview.com/urban-farming.html. Diakses pada tanggal 2 November 2021.

Rika Fitri. 2021. Peningkatan Pengetahuan Konsep Urbang Farming Pada Siswa SMA Negeri I Labuhan Deli Kabupaten Deli Serdang. Universitas Medan Area. Diakses Pada tanggal 1 November 2021. 